\title{
BMJ Autoantibody prevalence in active Open tuberculosis: reactive or pathognomonic?
}

\author{
Chieh-Yu Shen, ${ }^{1}$ Song-Chou Hsieh, ${ }^{1}$ Chia-Li Yu, ${ }^{1}$ Jann-Yuan Wang, ${ }^{1}$ Li-Na Lee, ${ }^{2}$ \\ Chong-Jen $\mathrm{Yu}^{1}$
}

To cite: Shen C-Y, Hsieh S-C, Yu C-L, et al. Autoantibody prevalence in active tuberculosis: reactive or pathognomonic?. BMJ Open 2013;3:e002665. doi:10.1136/ bmjopen-2013-002665

- Prepublication history for this paper is available online. To view these files please visit the journal online (http://dx.doi.org/10.1136/ bmjopen-2013-002665).

Received 31 January 2013 Revised 14 May 2013 Accepted 12 June 2013

${ }^{1}$ Department of Internal Medicine, National Taiwan University Hospital, Taipei, Taiwan

${ }^{2}$ Department of Laboratory Medicine, National Taiwan University Hospital, Taipei, Taiwan

\section{Correspondence to} Dr Jann-Yuan Wang; jywang@ntu.edu.tw

\section{ABSTRACT}

Objectives: To evaluate the autoantibody in patients without corresponding symptoms, whether these autoantibody are pathognomonic or not. We hypothesised that autoantibody may be reactive to chronic infection, such as tuberculosis (TB).

Design: Randomised, case-control cohort study. Setting: A tertiary centre in Taiwan.

Participants: We randomly chose 100 patients out of the data bank of patients with TB in a tertiary medical centre. All patients completed the sera sampling. We chose 100 patients according to autoantibody prevalence in previous literature. We also chose 100 medical staff as control group.

Interventions: We tested anti-SSA, anti-SSB, anti-Sm, anti ribonucleoprotein, anti-Scl 70, anticentromere, anti-double-stranded DNA, anticardiolipin IgG and IgM in all patient and control groups. The clinical symptoms and the underlying disease were all recorded.

Primary and secondary outcome measures: The result of sera antibody titre was recorded. For those with specific positive serology results, following examination was carried out after a 3-month anti-TB medication.

Results: Anticardiolipin IgG titre was significantly higher in patients with TB than in control group. We compared the result with previous population study and found that anti-Scl70 is also significantly higher in patients with TB. The following up data in anti-Scl70 revealed decreased titre after treatment. No correlation between sera titre and clinical conditions was observed.

Conclusions: In TB endemic areas, a significant proportion (32\%) of patients with TB have elevated autoantibody titres, especially anticardiolipin IgG and anti-Scl-70. Mycobacterial studies should be performed in patients with elevated serum autoantibody titres but without the typical or multiple manifestations of autoimmune diseases.

Trial registration: The study was approved by the Institutional Review Board of the hospital (NTUH REC: 9561707008) after informed consent had been obtained from the patients.

\section{INTRODUCTION}

Tuberculosis (TB) has become one of the most important diseases in the past two

\section{ARTICLE SUMMARY}

Article focus

- As chronic active tuberculosis (TB) has immunogenicity, autoantibodies are often found in patients with TB. Are there disease-specific autoantibodies in these patients? Are these autoantibodies pathognomonic even without the attendant symptomatology? Do they require immunosuppressant therapy? Can these diseasespecific autoantibodies be reactive to stimulation like TB even without corresponding symptoms?

Key message

- Disease-specific autoantibodies other than rheumatoid factor or antinuclear antibody exist in patients with TB. Autoantibody titres may decrease, even return to normal, as the infection is controlled. These findings suggest that autoantibodies are reactive to TB instead of being pathognomonic, and do not require immunosuppressant therapy.

Strengths and limitations of this study

- This is the first study to evaluate the clinical significance of autoantibodies by sequential data in TB. Despite the high probability of TB exposure and infection, medical staff serving as control patients may have higher prevalences of autoantibodies.

decades. It leads to organ dysfunction, mortality and various clinical manifestations. Previous studies have shown that sera from patients with active TB may contain autoantibodies that are unique in autoimmune diseases. The reported autoantibodies include rheumatoid factor (RF), antinuclear antibody (ANA), anticardiolipin antibody (ACA; IgM isotype predominant), antineutrophil cytoplasmic antibodies (ANCA) and anticyclic citrullinated peptide. ${ }^{1-4}$ Some of these are hallmarks of certain autoimmune diseases like rheumatoid arthritis, systemic lupus erythematosus (SLE) and ANCA-associated vasculitis. Some are even disease-specific, such as anticyclic citrullinated peptide in rheumatoid arthritis. ${ }^{5}{ }^{6}$ However, most studies are cross-sectional with limited case numbers and without definite correlations between 
serology and clinical manifestations. Little is known on the clinical significance (ie, pathognomonic, reactive or incidental) of autoantibodies in TB and the necessity of corticosteroid therapy.

Since patients with TB present with non-specific symptoms like fever, malaise and weight loss, clinicians may simultaneously order mycobacterial studies (acid-fast smear and mycobacterial culture) and autoimmune serology. Results of the latter usually become available earlier than results of the former. Thus, some patients with TB are put on systemic corticosteroids rather than anti-TB treatment, rendering the further dissemination of Mycobacterium tuberculosis bacilli. In this prospective cohort study, the prevalence of autoantibodies in patients with active TB was evaluated and compared with those of healthy controls. Dynamic changes in the autoantibodies were also monitored to investigate their clinical significance in patients with TB.

\section{PATIENTS AND METHODS}

\section{Patients and the study protocol}

The Institutional Review Board of the National Taiwan University Hospital (NTUH) approved this study (NTUH REC: 9561707008). To have a power of 0.8 and an $\alpha$ error of 0.95 in a two-sided test where the prevalence of ANA in patients with TB and the general population was $33 \%$ and $20 \%$, respectively, ${ }^{1}$ the calculated sample size was 83 for each. Therefore, from the 933 new cases of cultureconfirmed TB, diagnosed at the NTUH between January 2007 and December 2009, 100 were enrolled. All of the study participants provided written informed consent.

Among the 100 patients with TB, 96 had pure pulmonary TB, two had concomitant pulmonary and extrapulmonary $\mathrm{TB}$ (peritonitis in one and meningitis in another) and two had extrapulmonary TB only (neck lymphadenopathy in one and cutaneous $\mathrm{TB}$ in another). The first serum samples were collected before the start of anti-TB treatment. Blood was examined for autoantibodies to the Ro antigen, La antigen, centromere protein, double-stranded DNA (dsDNA), topoisomerase I (Scl-70), Smith protein, ribonucleoprotein particle (RNP), histone protein and histidyl-transfer RNA synthetase (Jo1). Anticardiolipin IgG and anticardiolipin IgM were also examined. For those with elevated serum autoantibody levels, follow-up serum samples were collected 3 months after anti-TB treatment to evaluate its effect on the autoantibody titres.

All of patients with TB received standard anti-TB treatment consisting of daily isoniazid (INH), rifampin (RIF), ethambutol and pyrazinamide in the first 2 months, followed by daily INH and RIF for the next 4 months. ${ }^{7}$ The regimen was modified by the primary care physician if necessary. One hundred healthy medical staff members were enrolled as the control group.

The clinical parameters collected were age, sex, underlying disease, clinical manifestations and radiographic findings of $\mathrm{TB}$, as well as adverse events during anti-TB treatment. Respiratory symptoms included cough, sputum, haemoptysis, dyspnoea and chest pain, while constitutional symptoms were fever, weight loss, general malaise and night sweats. The adverse events were classified into seven categories: (1) rheumatological, including cutaneous reaction and arthralgia; (2) gastrointestinal, including abnormal liver function, gastric discomfort, abdominal pain and change in bowel movement; (3) constitutional, including fever, poor appetite and malaise; (4) renal, including hyperuricaemia and impaired renal function; (5) neurological, including blurred vision, insomnia, delirium, headache and numbness; (6) respiratory, including cough, dyspnoea and chest pain and (7) haematological, including leukopenia, thrombocytopenia and anaemia.

As latent TB infection was more common in the medical staff than in the general population, ${ }^{8} 100$ healthcare workers were recruited as the control group for comparison. Household contacts of patients with TB might also have a high probability of latent TB infection but if relatives were used as control, ${ }^{9}$ the results might be confounded by similar environment and genetic components as the TB cases.

\section{Detection of autoantibodies}

A commercial test system AtheNA Multi-Lyte ANA-II Plus Test System was used to test IgG class antiextractable nuclear antigens, including autoantibodies to the Ro antigen, La antigen, centromere protein, dsDNA, Scl-70, Smith protein, RNP, histone protein and Jo1. Serum samples were prepared at 1:21 dilution and ELISA was performed according to the manufacturer's instructions.

A commercially available kit QUANTA Lite ACA IgM III was used to test anticardiolipin IgM. Sera were prepared at 1:101 dilution. The commercial kit Phadia Varelisa Cardiolipin IgG Antibodies EIA kit was used to test anticardiolipin IgG at serum dilution of 1:101. All ELISA assays were performed according to the manufacturers' instructions.

\section{Statistical analysis}

Intergroup difference was calculated using independentsamples $\mathrm{t}$ test for continuous variables and $\chi^{2}$ test or Fisher's exact test for categorical variables, as appropriate. Statistical significance was set at $\mathrm{p}<0.05$. All analyses were performed using the SPSS software V.12.0 for Windows.

\section{RESULTS}

The clinical characteristics of the 100 patients with TB were summarised in table 1 . The median age was 63 years (range, 19-92 years), with a male-to-female ratio of 2.03. Forty-one patients with TB had underlying diseases such as malignancy $(n=17)$, diabetes mellitus $(n=14)$, end-stage renal disease $(n=9)$ and one each with SLE, ankylosing spondylitis and rheumatoid arthritis. 
Table 1 Clinical characteristics of patients with autoantibody-positive and autoantibody-negative tuberculosis

\begin{tabular}{|c|c|c|c|}
\hline & Autoantibody-positive $(n=32)$ & Autoantibody-negative $(n=68)$ & p Value \\
\hline Respiratory symptoms & $22(69)$ & $46(68)$ & 0.912 \\
\hline Cough & $9(28)$ & $16(23)$ & 0.621 \\
\hline Sputum & $4(13)$ & 13 (19) & 0.411 \\
\hline Haemoptysis & $2(6)$ & $3(4)$ & 0.654 \\
\hline Dyspnoea & $5(16)$ & $10(15)$ & $>0.999$ \\
\hline Chest pain & $2(6)$ & $4(6)$ & $>0.999$ \\
\hline Constitutional symptoms & $14(44)$ & $21(31)$ & 0.208 \\
\hline Fever & $5(16)$ & 9 (13) & 0.763 \\
\hline Weight loss & $4(13)$ & $6(9)$ & 0.722 \\
\hline General malaise & $3(9)$ & $3(4)$ & 0.381 \\
\hline Night sweating & $2(6)$ & $3(4)$ & 0.654 \\
\hline \multicolumn{4}{|l|}{ Sputum smear grading } \\
\hline $3+\sim 4+$ & $2(6)$ & $8(12)$ & 0.495 \\
\hline $1+\sim 2+$ & $6(19)$ & $15(22)$ & 0.705 \\
\hline Negative & $24(69)$ & $45(66)$ & 0.373 \\
\hline Serum albumin $<3.5 \mathrm{~g} / \mathrm{dL}$ & $6(19)$ & $7(10)$ & 0.339 \\
\hline \multicolumn{4}{|l|}{ Radiographic findings } \\
\hline Bilateral infiltration & $10(31)$ & $34(50)$ & 0.078 \\
\hline Cavitations & $1(3)$ & $8(12)$ & 0.265 \\
\hline Pleural effusion & $5(16)$ & $11(16)$ & 0.944 \\
\hline Miliary lesion & 0 & $3(4)$ & 0.549 \\
\hline
\end{tabular}

Among the 17 patients with TB with malignancies, 6 had lung cancer, 3 had haematological malignancies, 4 had airway and lung malignancies, 2 had prostate cancer, 1 had breast cancer and 1 had pancreatic cancer.

The SLE patient was a middle-aged woman who presented as polyarthritis, malar rash and positive anti-dsDNA and antinuclear antibodies. She received disease-modifying antirheumatic drugs (DMARDs) and corticosteroids. The patient with ankylosing spondylitis was a young woman diagnosed by clinical symptoms and positive HLA-B27. She received non-steroidal antiinflammatory drugs (NSAIDs). The patient with rheumatoid arthritis was a young woman with symmetric polyarthritis with positive RF. She received DMARDs and NSAIDs. Before the diagnosis of pulmonary TB, results of autoantibody tests were all negative in these three patients.

Thirty-two patients with TB had elevated serum autoantibody levels, including nine with more than one autoantibody (table 1). The clinical manifestations and radiographic findings of the autoantibody-positive and antibody-negative groups were similar. Cough and sputum production were the most common respiratory symptoms, while fever and weight loss were the most common constitutional symptoms. Thirty-one patients were sputum smear positive for acid-fast bacilli.

Detailed results of the autoantibody tests were shown in table 2. The most prevalent autoantibodies in patients with TB were anti-Scl-70, antihistone and anticardiolipin IgG. A significantly higher proportion of patients with TB had elevated serum anticardiolipin IgG titres than the healthy controls $(p<0.001)$. Compared with a previous report on the prevalence of autoantibodies in the general population, ${ }^{10}$ patients with $\mathrm{TB}$ were more likely to have elevated serum titres of anti-Scl-70 $(\mathrm{p}<0.05)$ and anticardiolipin IgG $(\mathrm{p}<0.001)$. Among the anti-Scl-70-positive and anti-Scl-70-negative groups, $16 \%$ and $9 \%$, respectively, had pulmonary cavitation $(\mathrm{p}=0.441)$ and $33 \%$ and $16 \%$, respectively, had pleural effusion $(\mathrm{p}=0.245)$.

The median age of the healthy controls was 30 years, with a male-to-female ratio of 0.33 . None had underlying diseases. Though not statistically significant, the control group had a higher prevalence of anticardiolipin IgM than the TB group (table 2). Of the 10 healthy controls positive for anticardiolipin IgM, 8 had borderline titres that just passed the cut-off value. Among them, one was positive for anti-RNP and another for anti-histone antibodies. Of the six patients with TB positive for anticardiolipin IgM, four had borderline titres and one was positive for antihistone antibody.

Within 3 months of anti-TB treatment, 61 patients had 148 adverse events (table 3). The most common were rheumatological events, followed by gastrointestinal events. There was no significant difference in adverse events between patients with autoantibody-positive and autoantibody-negative TB.

For the 11 patients with elevated anticardiolipin IgG and 6 patients with elevated anti-Scl-70 at baseline, serum titres were followed up after 3 months of anti-TB treatment (table 4 ). None of the patients received immunosuppressants and DMARDs. Follow-up serum titres of anticardiolipin IgG and anti-Scl-70 returned to normal limits in seven and four patients, respectively. Among the five patients with persistently elevated anticardiolipin IgG or anti-Scl-70 autoantibodies, none had rheumatological symptoms at the end of the 6-month anti-TB treatment. 
Table 2 Prevalences of autoantibodies in patient with tuberculosis (TB), healthy controls and the general population ${ }^{10}$

\begin{tabular}{|c|c|c|c|c|c|c|c|}
\hline \multirow[b]{2}{*}{ Autoantibody } & \multicolumn{2}{|c|}{$\begin{array}{l}\text { Normal population } \\
(\mathrm{n}=2181)\end{array}$} & \multirow[b]{2}{*}{$\begin{array}{l}\text { Patients with } \\
\text { TB } \\
(n=100)\end{array}$} & \multirow[b]{2}{*}{$\begin{array}{l}\text { Healthy } \\
\text { control } \\
(n=100)\end{array}$} & \multicolumn{3}{|l|}{ p Value } \\
\hline & ELISA-pos & $\begin{array}{l}\text { Percentage of } \\
\text { pos }\end{array}$ & & & 3 Group & $\begin{array}{l}\text { TB vs } \\
\text { normal }\end{array}$ & $\begin{array}{l}\text { TB vs } \\
\text { control }\end{array}$ \\
\hline Anti-Ro & 58 & 2.7 & 2 & 2 & 0.855 & 1 & 1 \\
\hline Anti-La & 5 & 0.2 & 0 & 0 & 0.795 & 1 & 1 \\
\hline Anti-RNP & 11 & 0.5 & 2 & 1 & 0.138 & 0.108 & 1 \\
\hline Anti-Sm & 0 & 0 & 0 & 0 & & 1 & 1 \\
\hline Anti-Scl-70 & 0 & 0 & 6 & 3 & $<0.001$ & $<0.001$ & 0.498 \\
\hline Anti-Jo1 & 0 & 0 & 1 & 1 & $<0.001$ & 0.044 & 1 \\
\hline Anti-dsDNA & 10 & 0.5 & 1 & 0 & 0.579 & 0.39 & 1 \\
\hline Anticentromere & 30 & 1.4 & 5 & 2 & 0.101 & 0.059 & 0.683 \\
\hline Antihistone & NA & & 11 & 7 & & & 0.323 \\
\hline Anticardiolipin IgM & NA & & 6 & 10 & & & 0.297 \\
\hline Anticardiolipin IgG & NA & & 11 & 0 & & & 0.001 \\
\hline
\end{tabular}

\section{DISCUSSION}

The present study has three important findings. First, one-third of patients with active TB had elevated serum autoantibodies. The prevalences of their autoantibodies, especially anticardiolipin IgG and anti-Scl-70, were significantly higher than those of the general population. ${ }^{10}$ Second, consistent with previous studies, ${ }^{1-4}$ the presence of autoantibodies neither altered the clinical manifestations and radiographic findings of active TB nor changed the risk of developing adverse events during anti-TB treatment. Third, the elevated autoantibody levels returned to normal limits simply by anti-TB treatment and not by immunosuppressive therapy. These findings suggest that increased serum autoantibodies during active TB may not be diagnostic of autoimmune diseases. Clinical correlation and follow-up are still necessary.

Autoantibodies come from a break in self-tolerance whereby fragments of mixed self-antigens and pathogen antigens may induce immune response, as in a mode of epitope spread and autoantibody production. ${ }^{11} 12$ Epitope spread occurs when there is chronic inflammation, causing the immune system to produce a variety of antibodies against pathogens of chronic infections. Active TB is one of the most common infectious diseases causing long-term inflammation and tissue destruction. Thus, it is reasonable that autoantibodies are more common in patients with TB.

Clinically detectable autoantibodies are often characteristic of certain autoimmune diseases. ${ }^{13}$ However, like in other clinical examinations, all autoantibodies should be tested based on the corresponding clinical symptoms and signs. Most autoantibodies are pathognomonic of certain conditions, such as anti-dsDNA in SLE, ${ }^{14}$ anticyclic citrullinated peptide antibody in rheumatoid arthritis, ${ }^{6}{ }^{15}$ anti-Scl-70 in systemic sclerosis ${ }^{16}$ and anti-Jo- 1 in polymyositis. ${ }^{17}$ However, autoantibodies may also be present in conditions other than autoimmune diseases, especially when there are no corresponding clinical symptoms, such as RF in infective endocarditis ${ }^{18}$ and antiphospholipid syndrome secondary to infection or malignancy. ${ }^{19}$

The high prevalence of serum autoantibodies in active patients with TB has rarely been investigated and thus, remains unclear. If the autoantibodies are

Table 3 Adverse events during anti-tuberculosis (TB) treatment in patients with autoantibody-positive and antibody-negative TB

\begin{tabular}{llll}
\hline & Autoantibody-positive $(\mathbf{n = 3 2 )}$ & Autoantibody-negative $(\mathbf{n = 6 8 )}$ & $\mathbf{p ~ V a l u e ~}$ \\
\hline Rheumatological events & $10(31)$ & $28(41)$ & 0.340 \\
Gastrointestinal events & $9(28)$ & $22(32)$ & 0.670 \\
Neurological events & $8(25)$ & $16(24)$ & 0.872 \\
Renal events & $7(22)$ & $19(28)$ & 0.519 \\
Constitutional events & $4(13)$ & $19(28)$ & 0.087 \\
Respiratory events & $2(6)$ & $3(4)$ & 0.654 \\
Haematological events & $1(3)$ & 0.320 \\
Total number of events & 41 & 107 & \\
Data are number (\%). & &
\end{tabular}


Table 4 Serum autoantibody titres in patients with TB before and after anti-TB treatment

\begin{tabular}{|c|c|c|c|c|c|}
\hline \multirow[b]{2}{*}{ Patient No. } & \multicolumn{2}{|c|}{ Anti-Scl-70 } & \multirow[b]{2}{*}{ Patient No. } & \multicolumn{2}{|c|}{ ACA-IgG } \\
\hline & Initial & Follow-up & & Initial & Follow-up \\
\hline \multirow[t]{2}{*}{8} & 137 & 155 & 18 & 18.1 & 9.3 \\
\hline & & & 19 & 33.2 & 2.6 \\
\hline \multirow[t]{2}{*}{18} & 156 & 35 & 36 & 12.3 & 4.1 \\
\hline & & & 48 & 14.1 & 6.7 \\
\hline \multirow[t]{2}{*}{51} & 125 & 28 & 55 & 10.8 & 13.4 \\
\hline & & & 60 & 23.8 & 2.6 \\
\hline \multirow[t]{2}{*}{64} & 152 & 55 & 62 & 31.1 & 4.8 \\
\hline & & & 72 & 18.9 & 30.9 \\
\hline \multirow[t]{2}{*}{65} & 154 & 79 & 81 & 14.6 & 23.5 \\
\hline & & & 92 & 21.2 & 21.1 \\
\hline 91 & 153 & 68 & 94 & 12.8 & 5.1 \\
\hline
\end{tabular}

pathognomonic, there should be corresponding rheumatological symptoms and signs, especially in those with specific antiextractable nuclear antigen antibodies. Since the presence of autoantibodies does not alter the clinical manifestations and radiographic presentations of active TB, it is unlikely that autoantibodies have a pathognomonic role. ${ }^{1-4}$ In autoimmune diseases, serology titres of autoantibodies often change along with disease activity, such as anti-dsDNA in lupus nephritis. ${ }^{14}$ However, the finding that autoantibody titres return to normal limits after anti-TB treatment in more than two-thirds of patients with TB suggests the oppositethat the increase in autoantibodies is a reactive change during the disease course of active TB. This is a very important reminder.

If a patient has elevated autoantibody levels but no typical or multiple rheumatological symptoms, other possible aetiologies should be considered. For a patient in TB endemic areas, sputum samples for acid-fast smear and mycobacterial culture should be performed. If TB is missed and patients are diagnosed as having autoimmune diseases and treated with systemic corticosteroids, disseminated TB and TB-related mortality may occur.

The association of active TB and anticardiolipin IgG and antitopoisomerase I has not been previously reported. ACA is one of the hallmarks of antiphospholipid syndrome, which is known to be secondary to infectious diseases. ${ }^{19}$ Such antibody may be triggered by an infectious process that is non- $\beta_{2}$-glycoprotein 1-dependent. In active TB, mycobacterial phenolic glycolipids may activate neutrophils and release containers of ectosomes. $^{20}{ }^{21}$ Vesicles released from activated neutrophils that express phosphatidylserine and annexin $\mathrm{V}$ may be the epitopes of antiphospholipid antibodies. ${ }^{22} 23$ This may explain the high prevalence of anticardiolipin IgG in patients with TB. In general, the transient positivity of antiphospholipid antibody is not considered pathognomonic and does not meet the diagnostic criteria of antiphospholipid syndrome. ${ }^{19}$
However, some studies have different findings and show that patients with TB with diffuse alveolar haemorrhage have transient anticardiolipin IgG positivity. ${ }^{24} 25$ Moreover, in the present study, anticardiolipin IgG remained elevated in 4 of 11 patients even after 3 months of anti-TB treatment. Although anticardiolipin IgG is not diagnostic, a high index of suspicion should be maintained regarding their clinical manifestations, including thrombosis, haemorrhage, haemolytic anaemia and thrombocytopenia ${ }^{19}{ }^{26}$ in patients with $\mathrm{TB}$ with elevated anticardiolipin IgG.

Anti-Scl-70 is the first known prevalent autoantibody in patients with progressive systemic sclerosis. The autoantibody targets an antigen that is a $70 \mathrm{kDa}$ protein. Later studies reveal that Scl-70 should be the nuclear DNA topoisomerase I. ${ }^{27} 28$ Topoisomerase I is an enzyme that relaxes the strain on DNA by nicking and ligating it. One of the notorious manifestations of systemic sclerosis is interstitial lung disease, characterised by lung fibrosis. ${ }^{29}$ Although there is no significant difference, patients with $\mathrm{TB}$ in this study have elevated anti-Scl 70 and higher risk of pulmonary cavitation and pleural effusion. The underlying mechanisms involved are unclear since antigenic topoisomerase I is not a component of leukocyte ectosome. ${ }^{21}$ Moreover, it is not released from the TB bacilli because the structure of mycobacterial topoisomerase I is different from those of humans. ${ }^{30} 31$

In the present study, anti-Scl-70 titres returned to normal range after anti-TB treatment in all except one patient. The anti-Scl-70 antibody in active TB is probably secondary to pulmonary inflammation and destruction, which is uncovered by the nuclear topoisomerase I, thereby triggering the production of autoimmunity. The titre decreases once pulmonary injury is alleviated.

This study has some limitations. First, because the control group was composed of medical staff members, their baseline characteristics were very different from those of the TB group. This might lead to uncertainty in the prevalence of autoantibody in non-TB groups. Nonetheless, the autoantibody prevalence was still higher 
in patients with $\mathrm{TB}$ than in the general population reported in a previous publication. ${ }^{10}$ Second, follow-up samples were only obtained in those with elevated serum levels of autoantibodies before anti-TB treatment. Dynamic changes in autoantibodies might have been missed.

TB has a kaleidoscope of presentations that constantly challenge physicians. In TB endemic areas, a significant proportion $(32 \%)$ of patients with TB has elevated autoantibody titres, especially anticardiolipin $\mathrm{IgG}$ and anti-Scl-70. This phenomenon is likely to be reactive due to the lack of clinical correlations, as well as the spontaneous regression after TB treatment. Mycobacterial studies should be performed in patients with elevated serum autoantibody titres but without the typical or multiple manifestations of autoimmune diseases.

Acknowledgements The authors thank the staff of the Sixth and Eighth Core Labs, Department of Medical Research, and the Internal Medicine Lab of Immunology, National Taiwan University Hospital for their technical support.

Contributors J-YW and S-CH designed the study. C-YS, C-LY, S-CH, J-YW and $\mathrm{L}-\mathrm{NL}$ all contributed to the manuscript writing and data interpretation. $\mathrm{C}-\mathrm{YS}$ and $\mathrm{J}-\mathrm{YW}$ were involved in the statistical analysis. C-JY was directly responsible for the general organisation and instruction. All authors have read and approved the final manuscript.

Funding This study was supported by the National Science Council, Taiwan (grant NSC 101-2325-B-002-008) and the Research Centre for Biotechnology and Medicine Policy (grant DOH-101-DC-1101). The funders had no role in the study design, data collection and analysis, decision to publish or preparation of the manuscript.

Competing interests None.

Ethics approval The study was approved by the Institutional Review Board of the hospital (NTUH REC: 9561707008).

Provenance and peer review Not commissioned; externally peer reviewed.

Data sharing statement No additional data are available.

Open Access This is an Open Access article distributed in accordance with the Creative Commons Attribution Non Commercial (CC BY-NC 3.0) license, which permits others to distribute, remix, adapt, build upon this work noncommercially, and license their derivative works on different terms, provided the original work is properly cited and the use is non-commercial. See: http:// creativecommons.org/licenses/by-nc/3.0/

\section{REFERENCES}

1. Elkayam O, Caspi D, Lidgi M, et al. Auto-antibody profiles in patients with active pulmonary tuberculosis. Int $J$ Tuberc Lung Dis 2007;11:306-10.

2. Adebajo $A O$, Charles $P$, Maini RN, et al. Autoantibodies in malaria, tuberculosis and hepatitis $B$ in a west African population. Clin Exp Immunol 1993;92:73-6.

3. Ganesh R, Ramalingam V, Eswara Raja T, et al. Antinuclear antibodies in Mycobacterium tuberculosis infection. Indian J Pediatr 2008;75:1188

4. Kasikovic-Lecic S, Kerenji A, Pavlovic S, et al. Autoantibodies in patients treated for active pulmonary tuberculosis. Med Pregl 2008;61:333-42.

5. Aletaha D, Neogi T, Silman AJ, et al. 2010 rheumatoid arthritis classification criteria: an American College of Rheumatology/ European League Against Rheumatism collaborative initiative. Ann Rheum Dis 2010;69:1580-8.

6. Rantapaa-Dahlqvist S, de Jong BA, Berglin E, et al. Antibodies against cyclic citrullinated peptide and IgA rheumatoid factor predict the development of rheumatoid arthritis. Arthritis Rheum 2003;48:2741-9.

7. Lu K-T, eds. Taiwan guidelines for TB diagnosis and treatment. Taipei, Taiwan: Centers for Disease Control, R.O.C. (Taiwan), 2011.
8. Laniado-Laborin R, Cabrales-Vargas N. Tuberculosis in healthcare workers at a general hospital in Mexico. Infect Control Hosp Epidemiol 2006;27:449-52.

9. Wang JY, Shu CC, Lee CH, et al. Interferon-gamma release assay and Rifampicin therapy for household contacts of tuberculosis. $J$ Infect 2012;64:291-8.

10. Hayashi N, Koshiba M, Nishimura K, et al. Prevalence of disease-specific antinuclear antibodies in general population: estimates from annual physical examinations of residents of a small town over a 5-year period. Mod Rheumatol 2008;18:153-60.

11. Siegel RM, Lipsky PE. Autoimmunity. In: Firestein MGS, Budd RC, Harris ED Jr, Mclnnes IB, Ruddy S, Sergent JS, MD. eds. Kelley's textbook of rheumatology. Philadelphia: Elsevier Inc, 2009:270.

12. Powell AM, Black MM. Epitope spreading: protection from pathogens, but propagation of autoimmunity? Clin Exp Dermatol 2001;26:427-33.

13. Peng SL, Craft JE. Antinuclear antibodies. In Firestein MGS, Budd RC Harris ED Jr, McInnes IB, Ruddy S, Sergent JS, MD. eds. Kelley's textbook of rheumatology. Philadelphia: Elsevier, 2009:1623.

14. Tassiulas IO, Boumpas DT. Clinical features and treatment of systemic lupus erythematosus. In: Firestein MGS, Budd RC, Harris ED Jr, Mclnnes IB, Ruddy S, Sergent JS, MD. eds. Kelley's textbook of theumatology. Philadelphia: Elsevier, 2009:1273.

15. Kuhn KA, Kulik L, Tomooka B, et al. Antibodies against citrullinated proteins enhance tissue injury in experimental autoimmune arthritis. J Clin Invest 2006;116:961-73.

16. Varga J, Denton CP. Systemic sclerosis and the scleroderma-spectrum disorders. In: Firestein MGS, Budd RC, Harris ED Jr, Mclnnes IB, Ruddy S, Sergent JS, MD. eds. Kelley's textbook of rheumatology. Philadelphia: Elsevier, 2009:1323.

17. Nagaraju K, Lundberg IE. Inflammatory disease of muscle and other myopathies. In: Firestein MGS, Budd RC, Harris ED Jr, Mclnnes IB, Ruddy S, Sergent JS, MD. eds. Kelley's textbook of rheumatology. Philadelphia: Elsevier, 2009:1356.

18. Li JS, Sexton DJ, Mick N, et al. Proposed modifications to the Duke criteria for the diagnosis of infective endocarditis. Clin Infect Dis 2000;30:633-8.

19. Miyakis S, Lockshin MD, Atsumi T, et al. International consensus statement on an update of the classification criteria for definite antiphospholipid syndrome (APS). J Thromb Haemost 2006;4:295-306.

20. Faldt J, Dahlgren C, Karlsson A, et al. Activation of human neutrophils by mycobacterial phenolic glycolipids. Clin Exp Immunol 1999;118:253-60.

21. Gasser O, Hess C, Miot S, et al. Characterisation and properties of ectosomes released by human polymorphonuclear neutrophils. Exp Cell Res 2003;285:243-57.

22. Lopez LR, Dier KJ, Lopez D, et al. Anti-beta 2-glycoprotein I and antiphosphatidylserine antibodies are predictors of arterial thrombosis in patients with antiphospholipid syndrome. Am J Clin Pathol 2004;121:142-9.

23. Galli M, Comfurius $\mathrm{P}$, Maassen $\mathrm{C}$, et al. Anticardiolipin antibodies (ACA) directed not to cardiolipin but to a plasma protein cofactor. Lancet 1990;335:1544-7.

24. Deane KD, West SG. Antiphospholipid antibodies as a cause of pulmonary capillaritis and diffuse alveolar hemorrhage: a case series and literature review. Semin Arthritis Rheum 2005;35:154-65.

25. Almerico Marruchella AC, Tommasi C, Lauria FN, et al. A case of pulmonary tuberculosis presenting as diffuse alveolar haemorrhage: is there a role for anticardiolipin antibodies? BMC Infect Dis 2010;10:33.

26. Erkan D, Lockshin MD. Non-criteria manifestations of antiphospholipid syndrome. Lupus 2010;19:424-7.

27. Guldner $\mathrm{HH}$, Szostecki $\mathrm{C}$, Vosberg $\mathrm{HP}$, et al $\mathrm{Scl} 70$ autoantibodies from scleroderma patients recognize a $95 \mathrm{kDa}$ protein identified as DNA topoisomerase I. Chromosoma 1986;94:132-8.

28. Shero $\mathrm{JH}$, Bordwell B, Rothfield NF, et al. High titers of autoantibodies to topoisomerase I (Scl-70) in sera from scleroderma patients. Science 1986;231:737-40.

29. Rizou C, loannidis JP, Panou-Pomonis E, et al. B-Cell epitope mapping of DNA topoisomerase I defines epitopes strongly associated with pulmonary fibrosis in systemic sclerosis. Am J Respir Cell Mol Biol 2000;22:344-51.

30. Annamalai T, Dani N, Cheng B, et al. Analysis of DNA relaxation and cleavage activities of recombinant Mycobacterium tuberculosis DNA topoisomerase I from a new expression and purification protocol. BMC Biochem 2009;10:18

31. Narula G, Becker J, Cheng B, et al. The DNA relaxation activity and covalent complex accumulation of Mycobacterium tuberculosis topoisomerase I can be assayed in Escherichia coli: application for identification of potential FRET-dye labeling sites. BMC Biochem 2010;11:41. 